\title{
POLICY LEARNING \\ FROM COVID-19 \\ IN EUROPE
}


Executive Summary

-What lessons did European countries, individually and collectively, draw from their own experiences and from
the policy responses of neighbouring countries when Europe was the epicentre of the COVID-19 pandemic? -Were decision-takers better prepared to contain further waves of the disease and to improve outcomes?

The relative success of East Asian countries in controlling the spread of COVID-19 at its onset was widely attributed to their capacity to learn from previous experience of epidemics, their preparedness to deal with new threats to virus. The conditions were very different when Europe was recognised as the epicentre of the pandemic in March 2020. In a climate of uncertainty, intensified by inconsistent scientific advice and intractable political dilemmas, on limited and often conflicting evidence about their effectiveness in preventing transmission of the disease and high excess death rates, amid growing concern about the collateral damage being caused to public health, and to social and economic life.

Drawing on a wide range of multi-disciplinary published materials and official statistics, research articles, reports, during the first wave of the pates, as well as media headlines and commentary, this briefing assesses policy learning

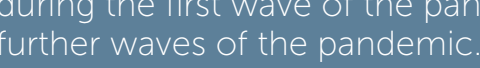

Last updated January 202

This briefing gives the views of the author. not the position of the London School of Economics and Political Science or Loughborough Universty

\section{Introduction}

What did governments in European Union member states and the UK learn from being at the epicentre of the COVID-19 pandemic?

Were they able to apply the lessons learnt within and between countries about the costs and benefits of the policy responses adopted in dealing with further outbreaks of the disease?

Politicians and the media frequently used comparisons of the performances of different countries in controlling COVID-19 to apportion blame for the failures of government responses. This briefing is designed to help decision-takers understand why certain policy responses worked or did not work in different European countries during the first and subsequent waves of the pandemic. It argues that, to improve the effectiveness of policy responses to the global threats posed by the pandemic for public health, social and economic well-being, more attention needs to be paid to contextual factors, the value of knowledge exchange, cross-border cooperation and public engagement.

\section{Issues with data collection and reporting}

- Reported cases and deaths may be daily, weekly/biweekly average or cumulative over time, presented as absolute numbers or per million inhabitants.

- Daily counts are distorted when deaths occurring at weekends are not reported until the following week producing momentary troughs and spikes.

- Data sources (national statistical offices, national and regional health authorities) produce statistics for different purposes; national statistics conceal regional variations. - Place of death can be in hospitals, care homes or the community, whereas only COVID deaths in hospitals were reported initially leading to spikes in the data if deaths in the community were belatedly added to cumulative counts of hospital deaths.

\section{Scientists advise}

Unlike East Asian countries which had experienced previous acute respiratory syndromes, Europe was ill-prepared for the new virus because

- the knowledge base was limited

- COVID-19 was recognised as a novel and virulent strain of coronavirus (C for corona, Vl for virus and D for disease) against which populations had no natural immunity - no vaccines or proven therapeutic strategies were available with which to fight the disease

While politicians at national level claimed to base their decisions on the best scientific evidence, teams of biostatisticians, virologists, epidemiologists, clinicians and statistical modellers cooperated across national boundaries - to build worldwide databases providing regularly updated information about every conceivable aspect of the disease - to increase knowledge about the behaviour of the virus, its symptoms, incubation, mutations, transmission and lethality

\section{Findings}

In March 2020 when Europe was recognised as the epicentre of the pandemic, many of the larger and/or more densely populated EU member states saw the numbers of COVID-19 deaths rise steeply. By mid-April, the pandemic was spiralling out of control in these same countries, whil most of the smaller and more recent Eastern European member states remained relatively untouched Headline statistics cited by the media and opposition politicians comparing the performances of countries were difficult to interpret owing to discrepancies in the data gathered to track the spread of the virus and its lethality. Datasets were inconsistent both within and between countries, making projections based on current figures unreliable and misleading. Miscounting attributable to misdiagnoses, missing data and under-reporting mean that the number of undetected cases and COVID-19 associated deaths were estimated to be several multiples greater than in published cumulative counts. These data limitations hampered scrutiny of the spread of the virus and understanding of its aetiology across Europe and beyond.

- Symptoms may be suspected presumptive or probable, unless confirmed by testing: the virus may be recorded as the main cause of death, a contributing factor or as simply present when death is due to nother condition.

- Asymptomatic cases can be missed even if a members of a population are tested frequently and systematically using reliable testing kits.

- Case fatality rates are likely to be misleading since variables for both cases and deaths are unreliable. - Excess mortality rates, where available, provide a more accurate account of the direct and indirect effects (collateral damage) of the virus on public health.

- to develop global interactive online tools to track the spread of the pandemic in real time (nowcasts), identify cumulative trends in the numbers of infections and deaths, and predict (forecast) how it might progress

- to make available reliable and operational testing and tracing tools,
interventions.

In their advice to governments, scientists disagreed on how best to gain control over the virus. For example. signatories to the Great Barrington Declaration advocated seeking herd immunity for the population at large. accompanied by focused protection of the vulnerable. an approach strongly disputed by scientists in the John Snow Memorandum on both ethical and practical grounds. Scientific modelling was criticised for basing its assumptions on inappropriate paradigms when determining rates of transmissibility, clinical severity and community spread, and the age groups most likely to be affected. 


\section{Building the scientific evidence base during the first wave of the pandemic}

\section{Transmission}

- COVID-19 is transmissible through direct human-to-

human contact via small respiratory droplets inhaled or picked up from surfaces by touching the nose, mouth or eyes.

- The disease spreads more easily and can cause more serious illness than seasonal influenza.

- The virus is transmitted most rapidly in crowded, poorly ventilated enclosed spaces and is therefore most virulent in cold weather.

- In the absence of protective measures, one infected person on average affects two or three other people: $80 \%$ of COVID-19 cases could be traced to $20 \%$ (superspreaders) of those infected with the virus.

- The risk of contracting the disease increases with age: young children are less likely to contract and transmit the virus than young adults.

- Infection begins two to three days before symptoms appear; it is greatest during the symptomatic period even in mild cases; transmission may be asymptomatic. - Past infection lowers the risk of catching COVID-19 again; reinfection can occur; it may produce more serious symptoms and can be more transmissible.

\section{Lethality}

- Hospitalisation rates and the risk of dying from . underlying health conditions (hypertension, diabetes. cardiovascular or chronic respiratory diseases, and

- Older people living in long-term care facilities are more likely to die from the disease than the population in general.

\section{Governments decide}

As death rates peaked during April 2020, and economies collapsed, pressures intensified on governments and the scientific advisers to intervene to curb the spread of the virus while minimising damage to social and economic life. Despite the best efforts of the European Commission to encourage uniformity, during the first wave of the pandemic national and local administrations reacted by - unilaterally closing national borders and ratcheting up capacity to protect their own populations

- freeing up acute care beds and accessing supplies of personal protective equipment (PPE) and ventilators on he open market to prevent their health services from being overwhelmed

- resorting to emergency powers to legitimise

interventions to contain the virus

- implementing combinations of measures - from soft low-cost policies to national lockdown - at varying speeds, with different sequencing, degrees of stringency and means of enforcemen

- supporting fast-tracking digital technologies in conjunction with private sector companies, scaling up large data processing, implementing online retailing. home-working and education, and rolling-out testing kits and tracing apps

As predicted by the scientists, the epicentre moved away from Europe to the US and southern hemisphere during the summer months. Infections and death rates dipped. Attention shifted from dealing with the direct and indirect impacts of the pandemic on public health to restoring social and economic life to normality. Governments progressively relaxed restrictions: travel bans were lifted hospitality, entertainment and tourism sectors, schools and offices reopened, and pressures on public health services were momentarily eased.

During the first wave, working collaboratively across national and cultural boundaries

- scientists had demonstrated the value of knowledge exchange

- the evidence base had grown exponentially

- substantial progress had been made in implementing testing and tracing strategies, and in developing treatments and vaccines.

Politicians and their advisers began to take stock and learn from their experiences in preparation for the next wave of the pandemic. Decision-takers still did not know for certain - which measures had been most successful

- why some countries had fared better than others

- whether the public would continue to comply with the rules

- if they did, how long people would be prepared to accept restrictions on their daily lives.
Governments in the European countries hardest hit by the virus were held to account for their failure to gain control of the pandemic. They were criticised to varying degrees for - initial delays in closing their borders and introducing national lockdown

- not lifting lockdown more gradually

- inconsistent interventions

- confused messaging

- infringement of personal privacy

- poor political leadership.

\section{Implications}

A multidimensional analysis of data about the transmission and lethality of COVID-19 during the first wave of the pandemic reveals the deep-seated dilemmas governments must confront in balancing the costs and benefits of the policy options they adopt.

This approach also helps to explain why containing the virus, preventing excess mortality and avoiding future Outheaks of the disease proved to be more difficult odds were stacked against large, densely poputated. internationally connected countries, with high oldage dependency ratios and urban concentrations. The pandemic presented greater challenges for policymakers in regions where these underlying conditions were associated with poorly resourced public healthcare services, underdeveloped technological infrastructures, crowded living and working arrangements, entrenched socio-economic and political divisions, unstable or dysfunctional governments, sceptical electorates and hostile media

As the number of cases and deaths peaked in Europe for a second time in November/December 2020, the countries per million in abitants during the first wave spiked earlier. per mally at lower levels, suggesting that their governments may have learnt how to contain the spread and severity of the virus. Most of the Eastern European countries and several of the other smaller member states that had emerged seemingly unscathed from the first wave saw death rates surge to unprecedented levels, indicating that they may have squandered their initial advantages. Following temporary easing of restrictions auring the Following temporary easing of restrictions during the Christmas period, EU countries faced a third wave of the pandemic where new factors had come into play.

- Scientific evidence showed that a mutation of the virus had created a more transmissible strain causing cases and death rates to spiral out of control within Europe and beyond.

- Several vaccines had been approved by European and national medical regulatory agencies and were ready for distribution. 


\section{Recommendations}

These developments necessitated a review of policy responses.

-While progress is being made towards large-scale production and distribution of effective vaccines, governments must continue the learning process in preparation for future outbreaks and for life after the pandemic.

- Populations must learn to live with the pandemic in the knowledge that effective herd immunity may only be obtained when reliable vaccines contain the spread of the virus worldwide.

- Low-cost effective public health measures - wearing of face coverings, physical distancing, handwashing, good ventilation of indoor spaces, quarantining - must be maintained for the foreseeable future.

- Governments must take responsibility for ensuring adequate supplies of PPE, acute hospital beds, appropriately trained staff, the efficient procurement and delivery of vaccines.

- In formulating proactive evidence-based responses, decision-takers must take account of the sociodemographic, epidemiological and political diversity and inequalities between and within countries determining the transmission and lethality of COVID-19, and the impacts of the pandemic on social, economic and cultural life, as well as public reactions.

- National lockdown should be used as a last resort and for finite periods due to its harmful social, psychological and economic consequences.

- Restrictive measures - travel bans, closures of schools, universities, offices, retail outlets, hospitality, sporting and cultural venues, limits on events and gatherings, visits to care homes - need to be adapted in line with changing local conditions, new scientific evidence and policy learning, underpinned by government support for the worst affected workers and businesses to limit collateral damage.
- Hotspots within countries or regions, and individuals who are superspreaders, need to be identified using targeted testing and tracing regimes supported by focused measures and resources for disadvantaged social groups required to self-isolate.

- Responses to changing circumstances must be rapid and selective deploying a combination of policy measures in conjunction with financial and logistic support.

- To prevent crisis fatigue and complacency, and encourage compliant behaviours, interventions should be time-limited, proportionate, legally justified and circumscribed, supported by reliable scientific evidence and deployed in cooperation with regional and local administrative authorities

- Policymakers must use clear, transparent and consistent messaging in tune with the public mood, based on consensual evidence, and they must lead by example if they are to gain public trust and compliance.

- A realistic balance must be struck between safeguarding public health, managing economic recovery and limiting intrusions into personal lives.

- Decision-takers must be wary of using emergency powers as a license to introduce irreversible changes in the way people live, work, are educated, use their leisure and are cared for.

- Measures must be taken to alleviate the socio-economic, technological and health inequalities exacerbated by the pandemic at global, national and local levels.

- Opportunities should be exploited to enhance policy learning in preparation for emerging global crises.

Contact details Professor Linda Hantrais, London School of Economics and Political Sciences, L.Hantrais@lse.ac.uk; and Loughborough University, L.Hantrais@lboro.ac.uk.

\section{Further reading}

COVID-DEM Infohub (2020) List of country reports, Covid-19 and states of emergency, Verfassungsblog on matters constitutional. https://verfassungsblog.de/introduction-list-of-country-reports/

EuroMOMO (2020) Excess mortality: Z-scores by country, EuroMOMO graphs and maps, 15 June 2020. https://www.euromomo.eu/graphs-and-maps

Flinders, M. (2020) Democracy and the politics of coronavirus: trust, blame and understanding, Parliamentary Affairs, 23 June, pp. 1-20. https://doi.org/10.1093/pa/gsaa013

Full Fact (2021) Get the facts on the new coronavirus. https://fullfact.org/health/coronavirus/

Great Barrington Declaration (4 October 2020). https://gbdeclaration.org/

Hantrais, L. and Letablier, M-T. (2021) Comparing and Contrasting the Impact of the COVID-19 Pandemic in the European Union, Routledge. www.routledge.com/9780367691721

John Snow Memorandum (14 October 2020). https://www.johnsnowmemo.com/

The Lancet (2021) COVID-19 Resource Centre. https://www.thelancet.com/coronavirus/archive

Maor, M. and Howlett, M. (2020) Explaining variations in state COVID-19 responses: psychological, institutional, and strategic factors in governance and public policy-making, 25 September, Policy Design and Practice. https://doi.org/10.1080/25741292.2020.1824379

Our World in Data (2021) Data Explorer. https://ourworldindata.org/coronavirus-data-explorer

Springer Nature (2021) Coronavirus (COVID-19) Research Highlights.

https://www.springernature.com/gp/researchers/campaigns/coronavirus

Worldometer (2021) Covid-19 Definitions and Reported Cases and Deaths. https://www.worldometers.info/ coronavirus/about/\#definitions; https://www.worldometers.infocoronavirus/?referer=app 